\title{
Design and Implementation of Management System Based on JSP Technology
}

\author{
Ying Zhang \\ Department of Teaching Affairs Jilin Agricultural University, 130118, Changchun, China \\ jlauzy@126.com
}

Keywords: JSP Technology; Teaching Management System; B/S mode; JavaBeans; MVC

\begin{abstract}
The article introduces the total design and implementation of teaching management system based on JSP technology. The system took Brower/server as web access model, Tomcat as Web server and SQL Server 2000 as data access software. The web function implement of system was developed by using the technique of JSP and JDBC.
\end{abstract}

\section{Introduction}

Teaching management system is an important part of school education management. It in such aspects as teaching execution and management optimization plays an extremely important role. How to design and develop the suitable for their own relationship with the school of the school's teaching management system of teaching activities and the quality of teaching level, a good system of teaching management is to maintain the important guarantee of teaching order and implementation of teaching plan. In recent years, with the continuous expansion of colleges and universities recruit students, the difficulty of the teaching management is becoming more and more big, design a meet the school teaching management system is essential. So how to make better use of the computer as a secondary means of management, the development of stable and efficient management system, the current building is the key issue facing the campus information.

\section{System Design}

For the different needs of the institutions of higher learning for the management of existing teaching, it uses the Unified Modeling Language (UML) the standardized modeling design language for the whole system a variety of business needs[1]. Teaching management system application written in JSP (Java Server Pages) Web programming language, back-end database using Microsoft SQL Server 2005 as a background supporting database, Senior Java programming language and software architecture design using MVC three-tier architecture, Servlet The container is responsible for logic control, and receiving user feedback request by using JSP network programming language, initialization and call JavaBean component to send information to the system browser-side application JSP network programming language, JavaBean components in system with the JSP web programming languages and the Servlet container to execute the process of user requests, as shown in Fig. 1. 


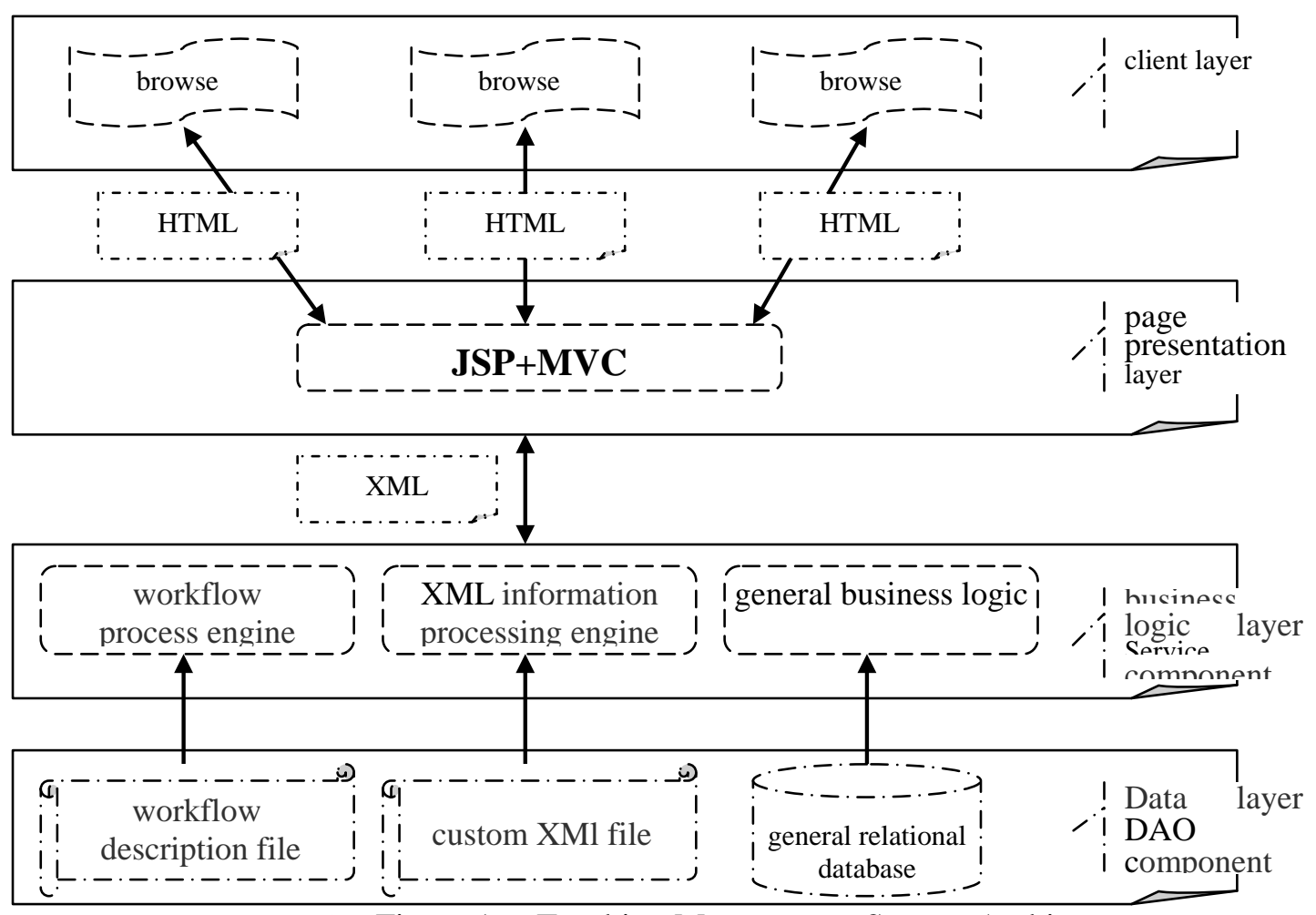

Figure 1. Teaching Management System Architecture

\section{System Function Modules}

The major objective of the teaching management system is to achieve the rational allocation of the teaching resources and the faculty resources. The setting of the curriculum timetable lies at the core of the system, which involves differences classes, teachers, classrooms, time and courses. The analysis of the application objectives of the system shows that the teaching management modules should include the management of different colleges, courses, classrooms, semesters, majors, teaching and research office, teachers, specialized courses, classrooms for different majors, holidays and festivals, grades and classes. Each module can have their information added, modified, deleted and so on[2]. The design of the teaching management system module is shown in Fig.2. 


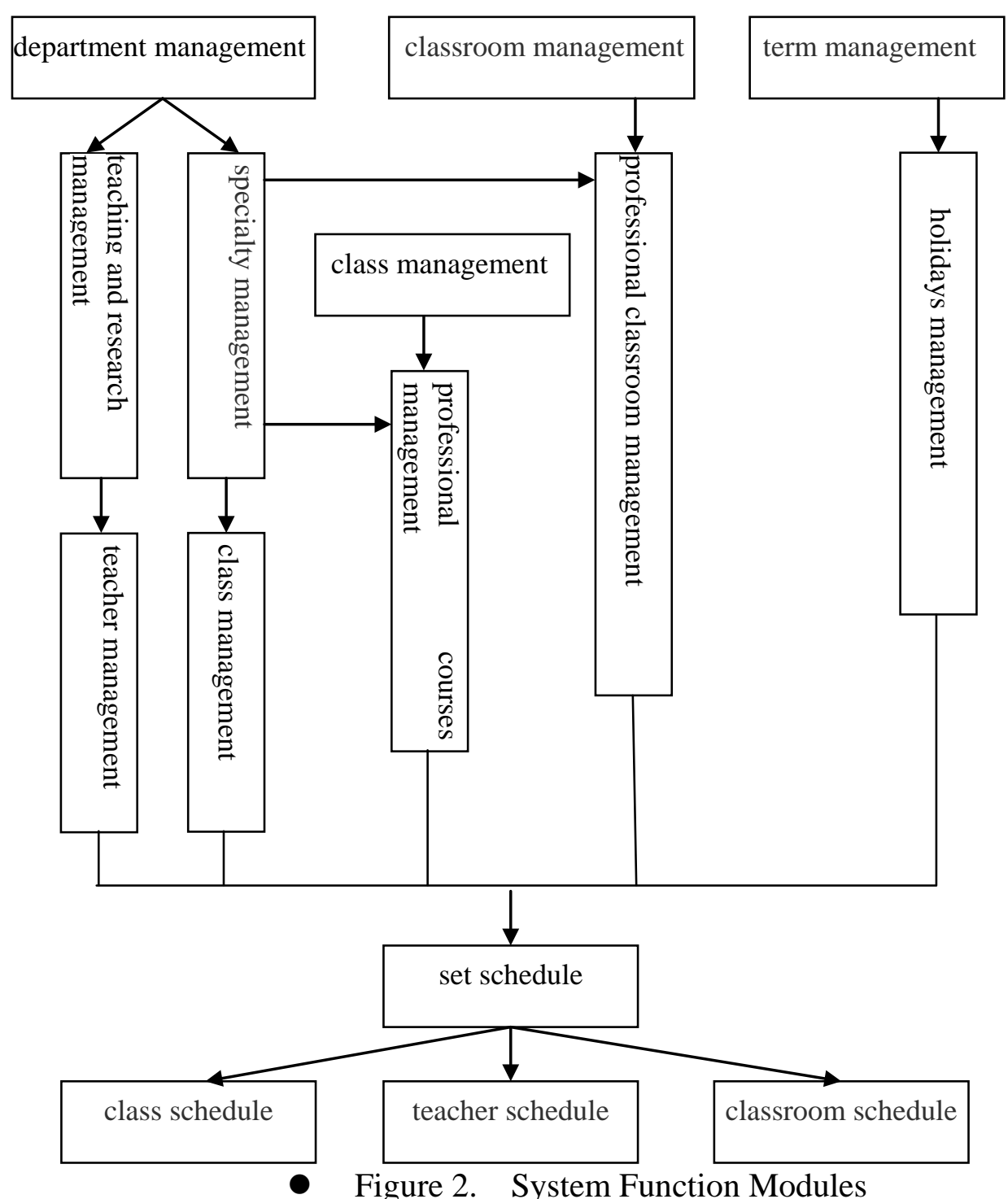

In the management module of colleges, it is mainly to achieve the management of different colleges in institutions of higher learning. The college information mainly includes the college name, its brief introduction, etc. Under the module, two sub-modules are set up, including the module of the teaching and research module and the module of majors. This means a college is made up of several teaching and research offices and majors.

In terms of the management module of teachers, it is mainly to achieve the management of the teachers' information, which includes the name, gender, nationality, degree, professional title and other aspects of teachers. When the curriculum timetable is set, it can quickly choose a teacher through the path of department $\rightarrow$ teaching and research office $\rightarrow$ teachers.

In terms of the management module of majors, it is mainly to achieve the management of different majors within a college. The professional information includes the name, brief introduction, schooling system, training plan, degree conferment and other aspects of the majors.

In terms of the management module of courses, it is mainly to achieve the unified management of all courses in school. Different majors might learn the same courses. However, due to difference of course starting time, learning hours, course nature, course type and other information, the other course information should be combined with the major. Thus, it is necessary to set the management module of the specialized courses[3]. 


\begin{tabular}{|c|c|}
\hline File Name & Explanation \\
\hline main.jsp & $\begin{array}{l}\text { practical teaching management } \\
\text { system main page }\end{array}$ \\
\hline register_form.jsp & user registration page \\
\hline login_form.jsp & user login page \\
\hline teach_list.jsp & teaching Information Page \\
\hline course_info.jsp & confirm course page \\
\hline upload_form.jsp & submit practical results page \\
\hline mark_ok.jsp & teacher score page \\
\hline request_list.jsp & evaluation and view page \\
\hline summary.jsp & written summary page \\
\hline
\end{tabular}

In terms of the management module of classrooms, it is mainly to achieve the management of all classrooms in school. The classroom information includes the name, location, number of seats and whether there are multimedia devices. Generally speaking, the classroom for a specialized course is relatively fixed. In order to minimize the scope of classrooms for specialized courses, the management module of classrooms for specialized courses is set up.

In terms of the management module of semesters, it is mainly to achieve the setting of the commencement date and deadline of a semester in certain academic year to form a calendar for the convenience of arranging courses in a fixed time zone and arranging different courses during the summer and winter vacations[4].

\section{main page design}

The list of the major pages is shown in Tab. 1.

\section{The module of course selection for students design}

The module of course selection for students is also a very important functional module of the Client. It is used to manage the course selection result of students[5]. The key code to achieve this is shown below:

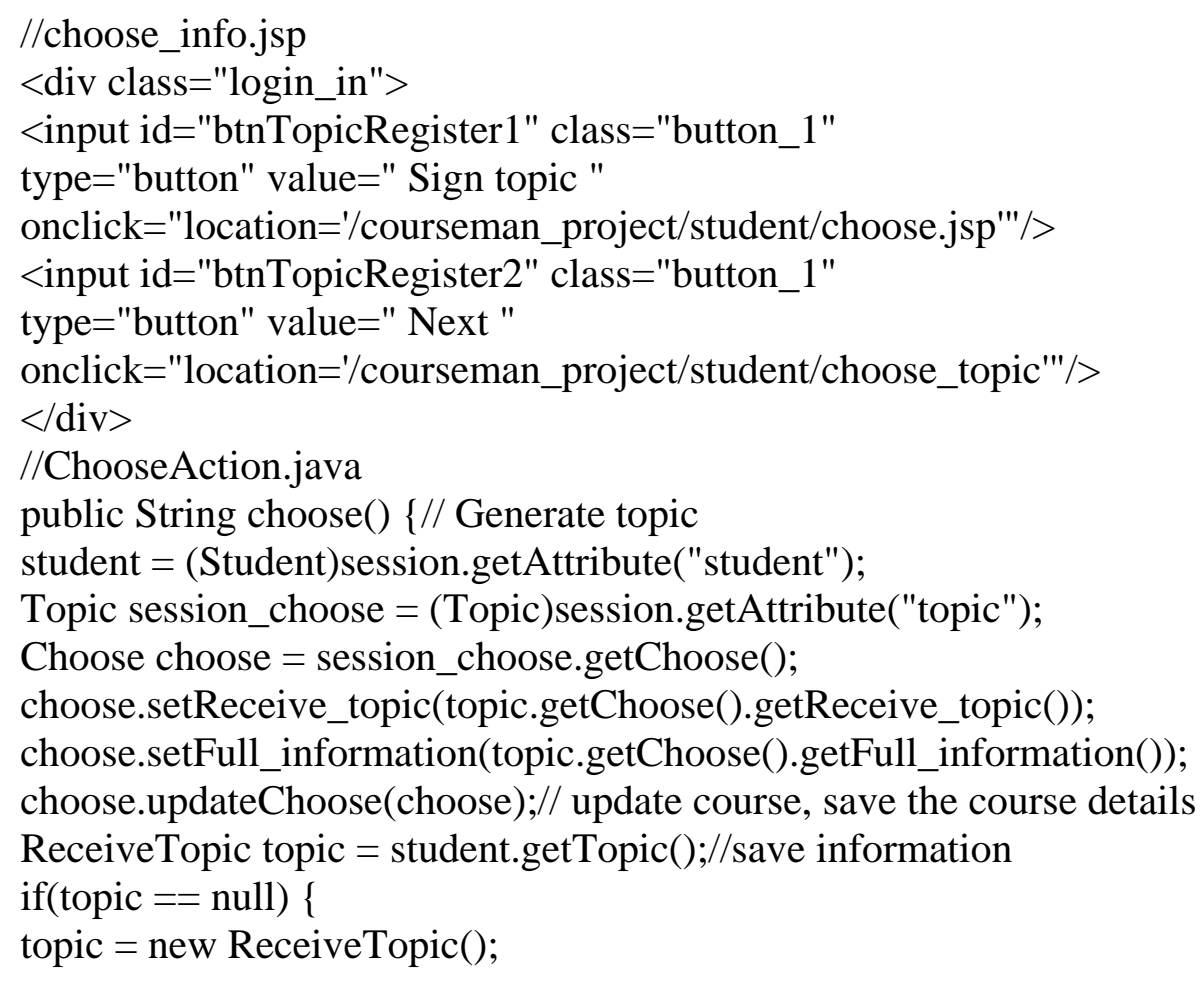


\}

topic.setFull_information(choose.getFull_information());

topic.setStuNo(choose.getStuNo());

student.setTopic(topic);

student.updateInformation(information);

session.removeAttribute("topic");

return "ChooseSuccess";

\}

\section{Conclusion}

This paper through research and teaching students in a college of integrated management systems, the functional and non-functional requirements of a university teaching management were analyzed by analysis of ftinctional and non-functional aspects related to the use J2EE JSP technology architecture and overall design concept system, key technologies, architecture, system functions in terms of structure and topology of the overall design of the system for a more detailed description of the design of the teaching management system based on MVC architecture and the use of SQL Server 2008 database system for a more in-depth research and design.

\section{References}

[1] R. L. Zhou, "Design and Implementation of Mixed Mode for Teaching Management System Based on C/5 and B/S,’Office Informatization, vol. 32, pp.58-59, Dec. 2009.

[2] C. Wang, "The Design and Implementation of Teaching Management System Based on ASP.NET,”Electronic Technology, vol. 12, pp.45-48, April 2014.

[3] A. Qu, "Study and design of college education and teaching management system based on Web Technology,”Electronic Test, vol. 20, pp.10-12, Sep. 2014.

[4] A. X. Chen, "Design and Implementation of University Experimental Teaching Management System,”Computer Knowledge and Technology, vol. 28, pp.1926-1927, Sep. 2014.

[5] C. D. Tang, "Wang Zhiping. Design and Implementation of Laboratory Teaching Management System in University,”Computer and Modernization, vol. 14, pp.113-116, Sep. 2013. 